\title{
Measuring the Brain-Gut Axis in Psychological Sciences: A Necessary Challenge
}

\author{
Ismael Palacios-García ${ }^{1,2 *}$ and Francisco J. Parada ${ }^{2}$ \\ ${ }^{1}$ Laboratorio de Psicofisiología, Escuela de Psicología, Pontificia Universidad Católica de Chile, Santiago, Chile, ${ }^{2}$ Laboratorio \\ de Neurociencia Cognitiva y Social, Facultad de Psicología, Universidad Diego Portales, Santiago, Chile
}

Keywords: brain, gastrointestinal system, psychology, neuroscience, 4E-cognition, microbiota

\section{INTRODUCTION}

The brain/body relationship and interdependence has been one of the most prevalent questions toward understanding psychobiological mechanisms underlying human behavior (Gover, 1996; Thompson and Varela, 2001). Current epistemological stances define brains as dynamic, complex, and self-organized systems (Cosmelli and Thompson, 2011), tightly coupled, and integrated with the rest of the body, establishing bidirectional communication axes (Thayer and Lane, 2000; Craig, 2002). The paradigmatic turn can be evidenced in an increment in scientific research considering both brain and bodily signals, such as the heart (Pollatos et al., 2007b; Villena-Gonzalez et al., 2017), respiration (Yuan et al., 2013; Ahani et al., 2014), gastrointestinal (Richter et al., 2017; Rebollo et al., 2018), and muscular dynamics (Boonstra et al., 2009, 2015; Kerkman et al., 2018). Recent evidence has furthermore revealed the many ways in which psychological processes influence the body, and vice-versa, with behavioral and health implications (Pollatos et al., 2007a; Mattson, 2015; Babo-Rebelo et al., 2016; Azzalini et al., 2019).

These ideas are products of continuous epistemological growth, already present at the end of behaviorism and the early days of the cognitive revolution. From Bartlett in the UK to Dewey

Edited by:

Pierre Denise,

INSERM U1075 Université de Caen

Normandie - Pôle des Formations et de Recherche en Santé, France

Reviewed by:

XiMa,

China Agricultural University

(CAU), China

*Correspondence: Ismael Palacios-García ipalacios@ug.uchile.cl

Received: 23 July 2019 Accepted: 09 December 2019 Published: 09 January 2020

Citation:

Palacios-García I and Parada FJ (2020) Measuring the Brain-Gut Axis in Psychological Sciences: A

Necessary Challenge. Front. Integr. Neurosci. 13:73. doi: 10.3389/fnint.2019.00073 in the USA to Luria in Moscow, many scientists had seen mind and brain as a whole with the body (Rossi et al., 2019). Like them, many other revolutionaries -whose work was unaffected by behaviorism- pushed forward the idea of a mind without the need for manipulation of abstract symbols and representations. However, the mainstream epistemological stance in Psychological and Cognitive Sciences still pursues the anthropogenic representational and computational capacities of the mind (Frégnac, 2017; Hari, 2017; Jonas and Kording, 2017).

\section{BODY SIGNALS INFLUENCE MOOD AND BEHAVIOR}

Research agendas including brain/body measurements are sustained in part by the fact that there are intrinsic cognitive mechanisms, related to body awareness and sense of self, integrating and monitoring visceral information; a process known as interoception (Craig, 2002; Slonim, 2014; Quadt et al., 2018). Interoception is a global concept encompassing a plethora of processes: neuro/humoral body-to-brain signals, neurocognitive dynamics associated to the integration of those signals, the influence of those dynamics on extended brain/body functional networks, and the associated unfolding of metacognitive processes (Valk et al., 2016; Quadt et al., 2018). High interoception has been associated with increased emotional regulation (Füstös et al., 2012) and decreased alexithymia (Herbert et al., 2011), depression (Avery et al., 2014), and anxiety (Garfinkel et al., 2016). Hence, it has been suggested that accurate sensing of visceral information and body awareness is a critical factor for psychological and emotional regulation, well-being (Hanley et al., 2017), and the basis for an integrated experience of the self (Christoff et al., 2011). 
The "Neural Subjective frame" hypothesis (Park and TallonBaudry, 2014) integrates evidence suggesting body signals can, non-consciously, modulate other cognitive processes like selfprocessing (Babo-Rebelo et al., 2016) and perception (Park et al., 2014). This hypothesis suggests that part of the emotional experience and perception is sustained by implicit and continuous brain monitoring of the internal organs of the body, such as the heart. These process would depend on autonomic signals mediated by the vagus nerve (Slonim, 2014).

It seems plausible that physical and mental well-being might depend on states emerging from implicit and explicit information associated with bodily signals (Critchley, 2005; Farb et al., 2012). Interestingly, one of the greatest sources of body information comes from the gastro-intestinal system (Park and TallonBaudry, 2014; Azzalini et al., 2019). This latter point has been an important focus of recent research and increasing evidence identifies gut microbiota as playing a functional role on cognition and emotion (Cryan and Dinan, 2012; Allen et al., 2017; Sarkar et al., 2018).

\section{GUT MICROBIOTA INFLUENCE BEHAVIOR}

The relationship between nervous and gastrointestinal systems is an example of psychobiological integration with direct impact on health, well-being (Grenham et al., 2011; Mayer et al., 2014; Carabotti et al., 2015; Fukui et al., 2018), and psychological states such as stress and anxiety (Mackos et al., 2016; Provensi et al., 2019). In fact, exposure to social stressors changes microbiota composition (Bailey et al., 2011) and diversity (Partrick et al., 2018), in a process that may also influence the immune function (Gur and Bailey, 2016). Interestingly, the treatment with bacteria of the Bifidobacterium and Lactobacillus genus confer resilience against effects of stress (Bharwani et al., 2017; Yang et al., 2017). It is worth mentioning that most of the evidence have been acquired using animal models. Hence, understanding the bidirectional role of psychological processes over microbiota in humans is still lacking. Microbiota would impact behavior via bottomup pathways, positioning it as a factor to consider in studies attempting the understanding of well-being (O'mahony et al., 2009; Dinan and Cryan, 2012; Dinan et al., 2013). Moreover, increasing evidence has posited microbiota as relevant in the context of autism (Mulle et al., 2013; Sgritta et al., 2019), schizophrenia (Severance et al., 2016), multiple sclerosis (Jangi et al., 2016), bipolar disorder (Evans et al., 2017), irritable bowel disease (Jeffery et al., 2012; Kennedy et al., 2014), obesity (Gomes et al., 2018), neurodegenerative disorders (Boehme et al., 2019), and depression (Naseribafrouei et al., 2014; Jiang et al., 2015; Aizawa et al., 2016; Kelly et al., 2016; Heym et al., 2019). The mechanisms through which microbiota exert its effects over behavior include neural pathways via the vagus nerve, regulation of the stress response, production of short chain fatty acids after fiber fermentation, amino acids metabolism and control of immune function, among others (Cryan and Dinan, 2012; Ma and Ma, 2019). The crosstalk between microbiota and immune cells is particularly relevant in therapeutic contexts, as a tight and complex relationship between dietary composition (amino acids) and inflammatory regulation by microbiota-dependent metabolic processes exists (Ma and Ma, 2019; Ma et al., 2019). Thus, positioning diet as a relevant therapeutic alternative for inflammatory-related conditions affecting brain and gut (KiecoltGlaser et al., 2017; Valdes et al., 2018).

Hence, growing evidence posits the gastrointestinal system in general -and the microbiota in particular- as a fundamental regulator of nervous system functioning (Agustí et al., 2018; Davidson et al., 2018) with clear neurobiological mechanisms (Cryan and Dinan, 2012; Ma and Ma, 2019) and potential impact on health and behavior. Our comprehension of cognitive and affective processes might depend on understanding the composition, diversity, and physiology of this ecosystem of microorganisms. In the fledgling field of gut-brain axis research, a plethora of novel questions emerge, some of them focused on understanding the particular role of specific bacterial strains on cognition, behavior, and overall brain function.

\section{THE USE OF PROBIOTICS AS A BEHAVIORAL REGULATOR}

Clinical population studies have pointed at the role of specific bacterial strains in brain function and their use as probiotics have adopted the name of psychobiotics (Dinan et al., 2013). For instance, patients diagnosed with depression present a decreased population of Bifidobacterium, Lactobacillus bacteria, and Faecalbacterium (Aizawa et al., 2016). Accordingly, psychobiotics with different combinations of strains have been used to assess their effects over depression symptoms in healthy participants and clinical population (Pirbaglou et al., 2016). For instance, depressive symptoms are diminished after 30 days of probiotic formulation with Lactobacillus helveticus and Bifidobacterium longum (Messaoudi et al., 2011). Likewise, patients diagnosed with irritable bowel syndrome scoring high in depression were treated with Bifidobacterium longum strain probiotics for 6 weeks, resulting in a significant decrease of subjective levels of depression (Pinto-Sanchez et al., 2017). Psychobiotics have also been used in the context of social/cognitive processes such as assessing attention (Chung et al., 2014), emotional processing (Tillisch et al., 2013) and stress (Allen et al., 2016). Additionally, it has been also shown that brain signatures under MRI setup- of healthy participants during an emotional memory and decision-making tasks are sensitive to 4-weeks of psychobiotic administration (Bagga et al., 2018). This effect was also accompanied with behavioral, self-reported and microbiota changes, suggesting that gut dynamics affect cognitive processes and the associated brain correlates.

The aforementioned results could be explained, in part, through bidirectional neural circuits established between the central nervous system, the enteric system, and the vagus nerve (Forsythe et al., 2014). This hypothesis has been tested using animal models in which anxiolytic and antidepressant effects induced by Bifidobacterium longum strains probiotics are blocked after the section of the vagus nerve (Bercik et al., 2011; Bravo et al., 2011). Hence, vagal afferents are necessary for any cognitive, affective, and behavioral effects produced by these 


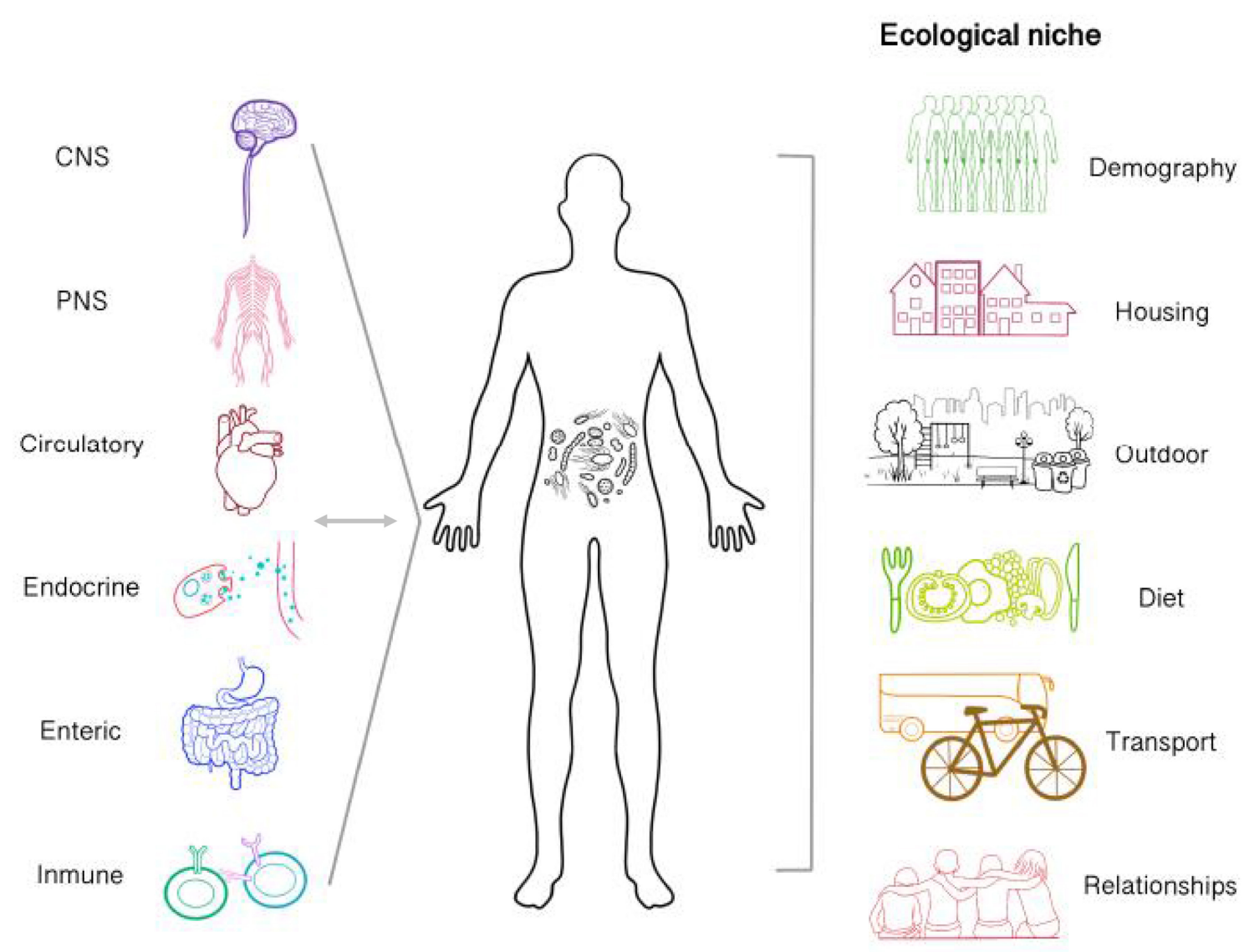

Physiological dynamics

FIGURE 1 | Microbiota establishes bi-directional relationships with physiological processes of the body and is affected by the ecological niche of which an agent participates. Gut microbiota interacts with other systems via neural and humoral pathways (Central, enteric and peripheral nervous system, immunoendocrine pathways, etc.). Possible communication mechanisms involve the regulation of neurotransmitter metabolism, gut permeability, nutrient processing and absorption, inflammatory cytokines release, the stress response, etc. Therefore, internal microbiota dynamics are actively affecting body dynamics in a process which in turn is also affecting microbiota. Microbiota in not only affected by internal processes but also by the agent's ecological niche. The features of the environment at different levels might be limited for the colonization and establishment of specific microbiological communities. Some environmental features which could be relevant includes the amount of people, the presence of the urban green space, urban hygiene, etc. Additionally, the ways by which the subject interact with it such as transportation, diet, and interpersonal relationships would also provide relevant information to take into account at the moment of carrying out interdisciplinary microbiota research.

microorganisms (Han et al., 2018). Additionally, a recent study identified a type of enteric sensory cell that, by means of a single synapse with neurons of the vagus nerve, propagates nutrient information from gut to brain in the order of milliseconds (Kaelberer et al., 2018). This communication channel may also include information from microbiota-dependent immune dynamics of the gut mucosa (Ma et al., 2018). Furthermore, low-frequency gastro-intestinal oscillations $(0.05 \mathrm{~Hz})$ and cortical alpha rhythms $(8-10 \mathrm{~Hz})$ coupling has been described (Richter et al., 2017), indicating that the cross-talk between gutmicrobiota and brain may be faster and more direct than previously thought. Complementarily, a gastric network was described during resting state involving connectivity between gastric oscillations and brain regions related to the generation of alpha rhythms and visual, somatosensory, and motor internal body representations (Rebollo et al., 2018). Those neural oscillatory networks could shed light on a possible physiological mechanism by means of which the microbiota communicates with the brain, exerting effects on mental processes in a fast and direct way (Komanduri et al., 2019). Nevertheless, this is a fledgling field and much research is still needed.

\section{DISCUSSION AND OUTSTANDING QUESTIONS}

When considering dynamics internal to the organism (Figure 1), understanding how the brain-gut-microbiota establishes bidirectional relationship offers new perspectives that will greatly advance our comprehension of phenomena studied by psychology, neuroscience, and psychiatry (Tillisch et al., 
2013; Dinan and Cryan, 2017). Given the increment of braingut-microbiota research, some important research questions have emerged. First, the physiological mechanisms underlying its relation to other body systems and health, in general, remains unknown in humans, resulting in limited clinical applicability (Schmidt et al., 2018; Zmora et al., 2019). Second, the establishment of microbiota communities begins early in development, even before birth. It has been suggested that pre- and postnatal experiences affect microbiota composition, shaping the immune system's function, ultimately leading to increased risk of disease (Tamburini et al., 2016; Francis and Dominguez-Bello, 2019). However, most countries are still far away from including the microbiota as a relevant factor for public policymaking. Finally, public opinion on probiotic products (from Kefir to Kombucha to laboratory formulas) has become favorable. However, recent evidence suggests that intake of generic probiotic formula as a therapeutic alternative should be carefully considered, as gut mucosal colonization presents person-specific resistance to probiotics (Zmora et al., 2018). Therefore, consuming such products as means of life-quality improvement and disease prevention might barely work. In contrast, it seems probiotic formulas will have to contain specific bacterial strains personalized for particular individuals, according to each person's diet (Oriach et al., 2016). Furthermore taking into account other physiological parameters relevant for the host-microbiota interplay, such as nutrients availability and water absorption (Arnoldini et al., 2018).

Considering the ecological niche of the organism presents a major challenge for microbiota research (Figure 1). Given the available evidence of living environment in mental health [i.e., housing quality, indoor/outdoor noise, occupant density, etc. (Evans, 2003)], the connection between the community of microorganisms residing in built environment and well-being remains unknown (Kembel et al., 2014; Relman et al., 2014). These microorganisms, grouped within the fledgling literature of the microbiome of the built environment (MoBE), have co-evolved with the mammalian immune system. Hence, there is a good reason to believe that the increment of chronic inflammatory disorders and others such as Alzheimer in industrialized countries might relate to reduced or increased exposure to certain microbial communities (Raison et al., 2010; Fox et al., 2013). Furthermore, research on the impact of MoBE in the development and dynamics of the community and/or person-specific microbiota is needed (Huttenhower et al., 2012; Hoisington et al., 2015; Lax et al., 2015). Thus, providing opportunities for specific and strategic MoBE manipulation that

\section{REFERENCES}

Agustí, A., García-Pardo, M. P., López-Almela, I., Campillo, I., Maes, M., RomaníPérez, M., et al. (2018). Interplay between the gut-brain axis, obesity and cognitive function. Front. Neurosci. 12:155. doi: 10.3389/fnins.2018.00155

Ahani, A., Wahbeh, H., Nezamfar, H., Miller, M., Erdogmus, D., and Oken, B. (2014). Quantitative change of EEG and respiration signals during mindfulness meditation. J. Neuroeng. Rehabilit. 11:87. doi: 10.1186/1743-0003$11-87$ will ultimately regulate microbial diversity in order to reach positive outcomes.

\section{CONCLUDING REMARKS}

Cognitive process and associated states such as well-being are embodied, in a process of phylogenetic and ontogenic interdependencies, encompassing an organism's both internal and external environments. Diurnal mammals' physiology has been enslaved by the day/night cycle, imposed to planet Earth from the cosmos (Parada and Rossi, 2018). Mammals' physiology is furthermore entangled to the micro-dynamics of small organisms, imposed onto the body through the development of a symbiotic relationship unfolding throughout ontogeny and phylogeny. Therefore, adequate scientific study of human behavior will include as many levels as possible: socio-cultural, psychological, microbiological, etc. (Parada and Rossi, 2018). The brain-gut-microbiota topic represents a fascinating opportunity to expand our knowledge about cognition, mental health, and life in general. It is important to frame this research topic from multiple perspectives including biological/medical sciences, public policy, architecture, urbanism, and psychology. Furthermore, recent philosophical and epistemological advances, under the 4E-cognition framework (Newen et al., 2018), will help the integration of evidence, providing new insights and novel hypotheses.

\section{AUTHOR CONTRIBUTIONS}

IP-G and FP conceptualized the present work and wrote the current version for publication.

\section{FUNDING}

The present work was supported by Comisión Nacional de Investigación Científica y Tecnológica (CONICYT, Chile), through FONDECYT postdoctorado grant number 3190491 awarded to IP-G. FONDECYT Iniciación en Investigación grant number 11180620 awarded to FP. FP also receives funding from FONDECYT Regular grant number 1190610. Both IP-G and FP also receive funding from FONDECYT Regular grant number 1170292 .

\section{ACKNOWLEDGMENTS}

The authors would like to thank Dr. Diego Cosmelli for insightful comments during the production of the present piece. (2016). Possible association of bifidobacterium and lactobacillus in the gut microbiota of patients with major depressive disorder. J. Affect. Disord. 202, 254-257. doi: 10.1016/j.jad.2016.05.038

Allen, A. P., Dinan, T. G., Clarke, G., and Cryan, J. F. (2017). A psychology of the human brain-gut-microbiome axis. Soc. Personal. Psychol. Compass 11:e12309. doi: $10.1111 /$ spc3.12309

Allen, A. P., Hutch, W., Borre, Y., Kennedy, P. J., Temko, A., Boylan, G., et al. (2016). Bifidobacterium longum 1714 as a translational psychobiotic: 
modulation of stress, electrophysiology and neurocognition in healthy volunteers. Transl. Psychiat. 6:e939. doi: 10.1038/tp.2016.191

Arnoldini, M., Cremer, J., and Hwa, T. (2018). Bacterial growth, flow, and mixing shape human gut microbiota density and composition. Gut Microbes 9, 559-566. doi: 10.1080/19490976.2018.1448741

Avery, J. A., Drevets, W. C., Moseman, S. E., Bodurka, J., Barcalow, J. C., and Simmons, W. K. (2014). Major depressive disorder is associated with abnormal interoceptive activity and functional connectivity in the insula. Biol. Psychiat. 76, 258-266. doi: 10.1016/j.biopsych.2013.11.027

Azzalini, D., Rebollo, I., and Tallon-Baudry, C. (2019). Visceral signals shape brain dynamics and cognition. Trends Cogn. Sci. 23, 488-509. doi: $10.1016 /$ j.tics.2019.03.007

Babo-Rebelo, M., Richter, C. G., and Tallon-Baudry, C. (2016). Neural responses to heartbeats in the default network encode the self in spontaneous thoughts. J. Neurosci. 36, 7829-7840. doi: 10.1523/JNEUROSCI.0262-16.2016

Bagga, D., Reichert, J. L., Koschutnig, K., Aigner, C. S., Holzer, P., Koskinen, K., et al. (2018). Probiotics drive gut microbiome triggering emotional brain signatures. Gut Microbes 9, 486-496. doi: 10.1080/19490976.2018.1460015

Bailey, M. T., Dowd, S. E., Galley, J. D., Hufnagle, A. R., Allen, R. G., and Lyte, M. (2011). Exposure to a social stressor alters the structure of the intestinal microbiota: implications for stressor-induced immunomodulation. Brain Behav. Immun. 25, 397-407. doi: 10.1016/j.bbi.2010.10.023

Bercik, P., Park, A., Sinclair, D., Khoshdel, A., Lu, J., Huang, X., et al. (2011). The anxiolytic effect of bifidobacterium longum NCC3001 involves vagal pathways for gut-brain communication. Neurogastroenterol. Motil. 23, 1132-1139. doi: 10.1111/j.1365-2982.2011.01796.x

Bharwani, A., Mian, M. F., Surette, M. G., Bienenstock, J., and Forsythe, P. (2017). Oral treatment with Lactobacillus rhamnosus attenuates behavioural deficits and immune changes in chronic social stress. BMC Med. 15:7. doi: 10.1186/s12916-016-0771-7

Boehme, M., Van De Wouw, M., Bastiaanssen, T. F., Olavarría-Ramírez, L., Lyons, K., Fouhy, F., et al. (2019). Mid-life microbiota crises: middle age is associated with pervasive neuroimmune alterations that are reversed by targeting the gut microbiome. Mol. Psychiatry, Vol. 1. doi: 10.1038/s41380-019-0425-1

Boonstra, T. W., Daffertshofer, A., Roerdink, M., Flipse, I., Groenewoud, K., and Beek, P. J. (2009). Bilateral motor unit synchronization of leg muscles during a simple dynamic balance task. Eur. J. Neurosci. 29, 613-622. doi: 10.1111/j.1460-9568.2008.06584.x

Boonstra, T. W., Danna-Dos-Santos, A., Xie, H.-B., Roerdink, M., Stins, J. F., and Breakspear, M. (2015). Muscle networks: connectivity analysis of EMG activity during postural control. Scienti. Rep. 5:17830. doi: 10.1038/srep17830

Bravo, J. A., Forsythe, P., Chew, M. V., Escaravage, E., Savignac, H. M., Dinan, T. G., et al. (2011). Ingestion of lactobacillus strain regulates emotional behavior and central GABA receptor expression in a mouse via the vagus nerve. Proc. Nat. Acad. Sci. U.S.A. 108, 16050-16055. doi: 10.1073/pnas.1102999108

Carabotti, M., Scirocco, A., Maselli, M. A., and Severi, C. (2015). The gut-brain axis: interactions between enteric microbiota, central and enteric nervous systems. Ann. Gastroenterol. 28, 203-209.

Christoff, K., Cosmelli, D., Legrand, D., and Thompson, E. (2011). Specifying the self for cognitive neuroscience. Trends Cogn. Sci. 15, 104-112. doi: 10.1016/j.tics.2011.01.001

Chung, Y.-C., Jin, H.-M., Cui, Y., Kim, D. S., Jung, J. M., Park, J.-I., et al. (2014). Fermented milk of lactobacillus helveticus IDCC3801 improves cognitive functioning during cognitive fatigue tests in healthy older adults. J. Funct. Foods 10, 465-474. doi: 10.1016/j.jff.2014.07.007

Cosmelli, D., and Thompson, E. (2011). "Embodiment or envatment? Reflections on the bodily basis of consciousness," in Enaction: Towards a New Paradigm for Cognitive Science, eds J. Stewart, O. Gapenne, and E. Di Paolo (Cambridge, MA: MIT Press), 361-385.

Craig, A. D. (2002). How do you feel? Interoception: the sense of the physiological condition of the body. Nat. Rev. Neurosci. 3, 655-666. doi: 10.1038/nrn894

Critchley, H. D. (2005). Neural mechanisms of autonomic, affective, and cognitive integration. J. Compar. Neurol. 493, 154-166. doi: 10.1002/cne.20749

Cryan, J. F., and Dinan, T. G. (2012). Mind-altering microorganisms: the impact of the gut microbiota on brain and behaviour. Nat. Rev. Neurosci. 13, 701-712. doi: $10.1038 / \mathrm{nrn} 3346$

Davidson, G. L., Cooke, A. C., Johnson, C. N., and Quinn, J. L. (2018). The gut microbiome as a driver of individual variation in cognition and functional behaviour. Philo. Trans. Royal Soc. Biol. Sci. 373:20170286. doi: 10.1098/rstb.2017.0286

Dinan, T. G., and Cryan, J. F. (2012). Regulation of the stress response by the gut microbiota: implications for psychoneuroendocrinology. Psychoneuroendocrinology 37, 1369-1378. doi: 10.1016/j.psyneuen.2012.03.007

Dinan, T. G., and Cryan, J. F. (2017). Brain-gut-microbiota axis and mental health. Psycho. Med. 79, 920-926. doi: 10.1097/PSY.0000000000000519

Dinan, T. G., Stanton, C., and Cryan, J. F. (2013). Psychobiotics: a novel class of psychotropic. Biol. Psychiatry 74, 720-726. doi: 10.1016/j.biopsych.2013.05.001

Evans, G. W. (2003). The built environment and mental health. J. Urban Health 80, 536-555. doi: 10.1093/jurban/jtg063

Evans, S. J., Bassis, C. M., Hein, R., Assari, S., Flowers, S. A., Kelly, M. B., et al. (2017). The gut microbiome composition associates with bipolar disorder and illness severity. J. Psychiat. Res. 87, 23-29. doi: 10.1016/j.jpsychires.2016.12.007

Farb, N. A., Segal, Z. V., and Anderson, A. K. (2012). Mindfulness meditation training alters cortical representations of interoceptive attention. Soc. Cognit. Affect. Neurosci. 8, 15-26. doi: 10.1093/scan/nss066

Forsythe, P., Bienenstock, J., and Kunze, W. A. (2014). "Vagal pathways for microbiome-brain-gut axis communication," in Microbial Endocrinology: The Microbiota-Gut-Brain Axis in Health and Disease (New York, NY: Springer), 115-133.

Fox, M., Knapp, L. A., Andrews, P. W., and Fincher, C. L. (2013). Hygiene and the world distribution of alzheimer's disease epidemiological evidence for a relationship between microbial environment and age-adjusted disease burden. Evol. Med. Pub. Health 2013, 173-186. doi: 10.1093/emph/eot015

Francis, A. P., and Dominguez-Bello, M. G. (2019). Early-life microbiota perturbations and behavioral effects. Trends Microbiol. 27, 567-569. doi: 10.1016/j.tim.2019.04.004

Frégnac, Y. (2017). Big data and the industrialization of neuroscience: a safe roadmap for understanding the brain? Science 358, 470-477. doi: $10.1126 /$ science.aan 8866

Fukui, H., Xu, X., and Miwa, H. (2018). Role of gut microbiota-gut hormone axis in the pathophysiology of functional gastrointestinal disorders. J. Neurogastroenterol. Motil. 24, 367-386. doi: 10.5056/jnm18071

Füstös, J., Gramann, K., Herbert, B. M., and Pollatos, O. (2012). On the embodiment of emotion regulation: interoceptive awareness facilitates reappraisal. Soc. Cognit. Affect. Neurosci. 8, 911-917. doi: 10.1093/scan/nss089

Garfinkel, S. N., Manassei, M. F., Hamilton-Fletcher, G., Den Bosch, Y. I., Critchley, H. D., and Engels, M. (2016). Interoceptive dimensions across cardiac and respiratory axes. Phil. Trans. R. Soc. B 371:20160014. doi: 10.1098/rstb.2016.0014

Gomes, A. C., Hoffmann, C., and Mota, J. F. (2018). The human gut microbiota: metabolism and perspective in obesity. Gut Microbes 9, 308-325. doi: 10.1080/19490976.2018.1465157

Gover, M. R. (1996). The embodied mind: cognitive science and human experience (book). Mind Cult. Activity 3, 295-299. doi: 10.1207/s15327884mca0304_9

Grenham, S., Clarke, G., Cryan, J. F., and Dinan, T. G. (2011). Braingut-microbe communication in health and disease. Front. Physiol. 2:94. doi: $10.3389 /$ fphys.2011.00094

Gur, T. L., and Bailey, M. T. (2016). "Effects of stress on commensal microbes and immune system activity," in Microbial Endocrinology: Interkingdom Signaling in Infectious Disease and Health. Advances in Experimental Medicine and Biology, Vol. 874, ed M. Lyte (Cham: Springer).

Han, W., Tellez, L. A., Perkins, M. H., Perez, I. O., Qu, T., Ferreira, J., et al. (2018). A neural circuit for gut-induced reward. Cell 175, 665-678. e623. doi: 10.1016/j.cell.2018.08.049

Hanley, A. W., Mehling, W. E., and Garland, E. L. (2017). Holding the body in mind: interoceptive awareness, dispositional mindfulness and psychological well-being. J. Psycho. Res. 99, 13-20. doi: 10.1016/j.jpsychores.2017.05.014

Hari, R. (2017). From brain-environment connections to temporal dynamics and social interaction: principles of human brain function. Neuron 94, 1033-1039. doi: 10.1016/j.neuron.2017.04.007

Herbert, B. M., Herbert, C., and Pollatos, O. (2011). On the relationship between interoceptive awareness and alexithymia: is interoceptive awareness related to emotional awareness? J. Personal. 79, 1149-1175. doi: 10.1111/j.1467-6494.2011.00717.x

Heym, N., Heasman, B., Hunter, K., Blanco, S., Wang, G., Siegert, R., et al. (2019). The role of microbiota and inflammation in self-judgement and empathy: 
implications for understanding the brain-gut-microbiome axis in depression. Psychopharmacology 236, 1459-1470. doi: 10.1007/s00213-019-05230-2

Hoisington, A. J., Brenner, L. A., Kinney, K. A., Postolache, T. T., and Lowry, C. A. (2015). The microbiome of the built environment and mental health. Microbiome 3:60. doi: 10.1186/s40168-015-0127-0

Huttenhower, C., Gevers, D., Knight, R., Abubucker, S., Badger, J. H., Chinwalla, A. T., et al. (2012). Structure, function and diversity of the healthy human microbiome. Nature 486:207. doi: 10.1038/nature11234

Jangi, S., Gandhi, R., Cox, L. M., Li, N., Von Glehn, F., Yan, R., et al. (2016). Alterations of the human gut microbiome in multiple sclerosis. Nat. Commun. 7:12015. doi: $10.1038 /$ ncomms 12015

Jeffery, I. B., O'toole, P. W., Öhman, L., Claesson, M. J., Deane, J., Quigley, E. M., et al. (2012). An irritable bowel syndrome subtype defined by species-specific alterations in faecal microbiota. Gut 61, 997-1006. doi: 10.1136/gutjnl-2011-301501

Jiang, H., Ling, Z., Zhang, Y., Mao, H., Ma, Z., Yin, Y., et al. (2015). Altered fecal microbiota composition in patients with major depressive disorder. Brain Behav. Immu. 48, 186-194. doi: 10.1016/j.bbi.2015.03.016

Jonas, E., and Kording, K. P. (2017). Could a neuroscientist understand a microprocessor? PLoS Comput. Biol. 13:e1005268. doi: 10.1371/journal.pcbi.1005268

Kaelberer, M. M., Buchanan, K. L., Klein, M. E., Barth, B. B., Montoya, M. M., Shen, X., et al. (2018). A gut-brain neural circuit for nutrient sensory transduction. Science 361:eaat5236. doi: 10.1126/science.aat5236

Kelly, J. R., Borre, Y., O’brien, C., Patterson, E., El Aidy, S., Deane, J., et al. (2016). Transferring the blues: depression-associated gut microbiota induces neurobehavioural changes in the rat. J. Psychiat. Res. 82, 109-118. doi: 10.1016/j.jpsychires.2016.07.019

Kembel, S. W., Meadow, J. F., O'connor, T. K., Mhuireach, G., Northcutt, D., Kline, J., et al. (2014). Architectural design drives the biogeography of indoor bacterial communities. PLoS ONE 9:e87093. doi: 10.1371/journal.pone.0087093

Kennedy, P. J., Cryan, J. F., Dinan, T. G., and Clarke, G. (2014). Irritable bowel syndrome: a microbiome-gut-brain axis disorder? World J. Gastroenterol. 20:14105. doi: 10.3748/wjg.v20.i39.14105

Kerkman, J. N., Daffertshofer, A., Gollo, L. L., Breakspear, M., and Boonstra, T. W. (2018). Network structure of the human musculoskeletal system shapes neural interactions on multiple time scales. Sci. Adv. 4:eaat0497. doi: 10.1126/sciadv.aat0497

Kiecolt-Glaser, J. K., Fagundes, C. P., Andridge, R., Peng, J., Malarkey, W. B., Habash, D., et al. (2017). Depression, daily stressors and inflammatory responses to high-fat meals: when stress overrides healthier food choices. Mol. Psychiatry 22:476. doi: 10.1038/mp.2016.149

Komanduri, M., Gondalia, S., Scholey, A., and Stough, C. (2019). The microbiome and cognitive aging: a review of mechanisms. Psychopharmacology 236, 1559-1571. doi: 10.1007/s00213-019-05231-1

Lax, S., Nagler, C. R., and Gilbert, J. A. (2015). Our interface with the built environment: immunity and the indoor microbiota. Trends Immunol. 36, 121-123. doi: 10.1016/j.it.2015.01.001

Ma, N., Guo, P., Zhang, J., He, T., Kim, S. W., Zhang, G., et al. (2018). Nutrients mediate intestinal bacteria-mucosal immune crosstalk. Front. Immunol. 9:5. doi: $10.3389 /$ fimmu. 2018.00005

Ma, N., Ma, X. (2019). Dietary amino acids and the gut-microbiome-immune axis: physiological metabolism and therapeutic prospects. Compre. Rev. Food Sci. Food Safety 18, 221-242. doi: 10.1111/1541-4337.12401

Ma, N., Zhang, J., Reiter, R. J., and Ma, X. (2019). Melatonin mediates mucosal immune cells, microbial metabolism, and rhythm crosstalk: a therapeutic target to reduce intestinal inflammation. Med. Res. Rev. p. 1-27. doi: $10.1002 /$ med.21628

Mackos, A. R., Varaljay, V. A., Maltz, R., Gur, T. L., and Bailey, M. T. (2016). "Role of the intestinal microbiota in host responses to stressor exposure," in International Review of Neurobiology, Vol. 131, eds J. F. Cryan and G. Clarke (London: Academic Press), 1-19.

Mattson, M. P. (2015). Lifelong brain health is a lifelong challenge: from evolutionary principles to empirical evidence. Ageing Res. Rev. 20, 37-45. doi: 10.1016/j.arr.2014.12.011

Mayer, E. A., Knight, R., Mazmanian, S. K., Cryan, J. F., and Tillisch, K. (2014). Gut microbes and the brain: paradigm shift in neuroscience. J. Neurosci. 34, 15490-15496. doi: 10.1523/JNEUROSCI.3299-14.2014
Messaoudi, M., Violle, N., Bisson, J.-F., Desor, D., Javelot, H., and Rougeot, C. (2011). Beneficial psychological effects of a probiotic formulation (lactobacillus helveticus R0052 and bifidobacterium longum R0175) in healthy human volunteers. Gut Microbes 2, 256-261. doi: 10.4161/gmic.2.4.16108

Mulle, J. G., Sharp, W. G., and Cubells, J. F. (2013). The gut microbiome: a new frontier in autism research. Curr. Psychiatry Rep. 15:337. doi: 10.1007/s11920-012-0337-0

Naseribafrouei, A., Hestad, K., Avershina, E., Sekelja, M., Linløkken, A., Wilson, R., et al. (2014). Correlation between the human fecal microbiota and depression. Neurogastroenterol. Motil. 26, 1155-1162. doi: 10.1111/nmo.12378

Newen, A., De Bruin, L., and Gallagher, S. (eds.). (2018). The Oxford Handbook of $4 E$ Cognition. Oxford: Oxford University Press.

O'mahony, S. M., Marchesi, J. R., Scully, P., Codling, C., Ceolho, A.-M., Quigley, E. M., et al. (2009). Early life stress alters behavior, immunity, and microbiota in rats: implications for irritable bowel syndrome and psychiatric illnesses. Biol. Psychiatry 65, 263-267. doi: 10.1016/j.biopsych.2008.06.026

Oriach, C. S., Robertson, R. C., Stanton, C., Cryan, J. F., and Dinan, T. G. (2016). Food for thought: the role of nutrition in the microbiota-gut-brain axis. Clini. Nutri. Exp. 6, 25-38. doi: 10.1016/j.yclnex.2016.01.003

Parada, F. J., and Rossi, A. (2018). If neuroscience needs behavior, what does psychology need? Front. Psychol. 9:433. doi: 10.3389/fpsyg.2018.00433

Park, H. D., Correia, S., Ducorps, A., and Tallon-Baudry, C. (2014). Spontaneous fluctuations in neural responses to heartbeats predict visual detection. Nat. Neurosci. 17, 612-618. doi: 10.1038/nn.3671

Park, H. D., and Tallon-Baudry, C. (2014). The neural subjective frame: from bodily signals to perceptual consciousness. Philos. Trans. R Soc. Lond. B Biol. Sci. 369:20130208. doi: 10.1098/rstb.2013.0208

Partrick, K. A., Chassaing, B., Beach, L. Q., Mccann, K. E., Gewirtz, A. T., and Huhman, K. L. (2018). Acute and repeated exposure to social stress reduces gut microbiota diversity in Syrian hamsters. Behav. Brain Res. 345, 39-48. doi: 10.1016/j.bbr.2018.02.005

Pinto-Sanchez, M. I., Hall, G. B., Ghajar, K., Nardelli, A., Bolino, C., Lau, J. T., et al. (2017). Probiotic bifidobacterium longum NCC3001 reduces depression scores and alters brain activity: a pilot study in patients with irritable bowel syndrome. Gastroenterology 153, 448-459. e448. doi: 10.1053/j.gastro.2017. 05.003

Pirbaglou, M., Katz, J., De Souza, R. J., Stearns, J. C., Motamed, M., and Ritvo, P. (2016). Probiotic supplementation can positively affect anxiety and depressive symptoms: a systematic review of randomized controlled trials. Nutri. Res. 36, 889-898. doi: 10.1016/j.nutres.2016.06.009

Pollatos, O., Gramann, K., and Schandry, R. (2007a). Neural systems connecting interoceptive awareness and feelings. Hum. Brain Map. 28, 9-18. doi: 10.1002/hbm.20258

Pollatos, O., Traut-Mattausch, E., Schroeder, H., and Schandry, R. (2007b). Interoceptive awareness mediates the relationship between anxiety and the intensity of unpleasant feelings. J. Anxiety Disord. 21, 931-943. doi: 10.1016/j.janxdis.2006.12.004

Provensi, G., Schmidt, S. D., Boehme, M., Bastiaanssen, T. F., Rani, B., Costa, A., et al. (2019). Preventing adolescent stress-induced cognitive and microbiome changes by diet. Proc. Nat. Acad. Sci. U.S.A. 116, 9644-9651. doi: 10.1073/pnas.1820832116

Quadt, L., Critchley, H. D., and Garfinkel, S. N. (2018). The neurobiology of interoception in health and disease. Ann. N.Y. Acad. Sci. 1428, 112-128. doi: 10.1111/nyas. 13915

Raison, C. L., Lowry, C. A., and Rook, G. A. (2010). Inflammation, sanitation, and consternation: loss of contact with coevolved, tolerogenic microorganisms and the pathophysiology and treatment of major depression. Archiv. Gener. Psychiatry 67, 1211-1224. doi: 10.1001/archgenpsychiatry.2010.161

Rebollo, I., Devauchelle, A.-D., Béranger, B., and Tallon-Baudry, C. (2018). Stomach-brain synchrony reveals a novel, delayed-connectivity resting-state network in humans. eLife 7:e33321. doi: 10.7554/eLife.33321.023

Relman, D. A., Gilbert, J. A., and Knight, R. (2014). The promise of the microbiome: function and dysfunction in humans and beyond. Science 345, 226-226. doi: 10.1126/science.345.6193.226-c

Richter, C. G., Babo-Rebelo, M., Schwartz, D., and Tallon-Baudry, C. (2017). Phaseamplitude coupling at the organism level: the amplitude of spontaneous alpha rhythm fluctuations varies with the phase of the infra-slow gastric basal rhythm. Neuroimage 146, 951-958. doi: 10.1016/j.neuroimage.2016.08.043 
Rossi, A., Grasso-Cladera, A., Luarte, N., Riillo, A., and Parada, F. J. (2019). The brain/body-in-the-world system is cognitive science's study object for the twenty-first century/El sistema cerebro/cuerpo-en-el-mundo es el objeto de estudio de la ciencia cognitiva en el siglo XXI. Estudios de Psicología 40, 363-395. doi: 10.1080/02109395.2019.1596704

Sarkar, A., Harty, S., Lehto, S. M., Moeller, A. H., Dinan, T. G., Dunbar, R. I., et al. (2018). The microbiome in psychology and cognitive neuroscience. Trends Cogn. Sci. 22, 611-636. doi: 10.1016/j.tics.2018.04.006

Schmidt, T. S., Raes, J., and Bork, P. (2018). The human gut microbiome: from association to modulation. Cell 172, 1198-1215. doi: 10.1016/j.cell.2018. 02.044

Severance, E. G., Yolken, R. H., and Eaton, W. W. (2016). Autoimmune diseases, gastrointestinal disorders and the microbiome in schizophrenia: more than a gut feeling. Schizophre. Res. 176, 23-35. doi: 10.1016/j.schres.2014.06.027

Sgritta, M., Dooling, S. W., Buffington, S. A., Momin, E. N., Francis, M. B., Britton, R. A., et al. (2019). Mechanisms underlying microbial-mediated changes in social behavior in mouse models of autism spectrum disorder. Neuron 101, 246-259. e246. doi: 10.1016/j.neuron.2018.11.018

Slonim, T. (2014). The polyvagal theory: neuropsychological foundations of emotions, attachment, communication, \& self-regulation. Int. J. Group Psychother. 64, 593-600. doi: 10.1521/ijgp.2014.64.4.593

Tamburini, S., Shen, N., Wu, H. C., and Clemente, J. C. (2016). The microbiome in early life: implications for health outcomes. Nat. Med. 22:713. doi: $10.1038 / \mathrm{nm} .4142$

Thayer, J. F., and Lane, R. D. (2000). A model of neurovisceral integration in emotion regulation and dysregulation. J. Affect. Disord. 61, 201-216. doi: 10.1016/S0165-0327(00)00338-4

Thompson, E., and Varela, F. J. (2001). Radical embodiment: neural dynamics and consciousness. Trends Cogn. Sci. 5, 418-425. doi: 10.1016/S1364-6613(00)01750-2

Tillisch, K., Labus, J., Kilpatrick, L., Jiang, Z., Stains, J., Ebrat, B., et al. (2013). Consumption of fermented milk product with probiotic modulates brain activity. Gastroenterology 144, 1394-1401. e1394. doi: 10.1053/j.gastro.2013.02.043
Valdes, A. M., Walter, J., Segal, E., and Spector, T. D. (2018). Role of the gut microbiota in nutrition and health. BMJ 361:k2179. doi: 10.1136/bmj.k2179

Valk, S. L., Bernhardt, B. C., Böckler, A., Kanske, P., and Singer, T. (2016). Substrates of metacognition on perception and metacognition on higher-order cognition relate to different subsystems of the mentalizing network. Hum. Brain Map. 37, 3388-3399. doi: 10.1002/hbm.23247

Villena-Gonzalez, M., Moenne-Loccoz, C., Lagos, R. A., Alliende, L. M., Billeke, P., Aboitiz, F., et al. (2017). Attending to the heart is associated with posterior alpha band increase and a reduction in sensitivity to concurrent visual stimuli. Psychophysiology 54, 1483-1497. doi: 10.1111/psyp.12894

Yang, C., Fujita, Y., Ren, Q., Ma, M., Dong, C., and Hashimoto, K. (2017). Bifidobacterium in the gut microbiota confer resilience to chronic social defeat stress in mice. Scienti. Rep. 7:45942. doi: 10.1038/srep45942

Yuan, H., Zotev, V., Phillips, R., and Bodurka, J. (2013). Correlated slow fluctuations in respiration, EEG, and BOLD fMRI. Neuroimage 79, 81-93. doi: 10.1016/j.neuroimage.2013.04.068

Zmora, N., Soffer, E., and Elinav, E. (2019). Transforming medicine with the microbiome. Sci. Transl. Med. 11:eaaw1815. doi: 10.1126/scitranslmed.aaw1815

Zmora, N., Zilberman-Schapira, G., Suez, J., Mor, U., Dori-Bachash, M., Bashiardes, S., et al. (2018). Personalized gut mucosal colonization resistance to empiric probiotics is associated with unique host and microbiome features. Cell 174, 1388-1405. e1321. doi: 10.1016/j.cell.2018.08.041

Conflict of Interest: The authors declare that the research was conducted in the absence of any commercial or financial relationships that could be construed as a potential conflict of interest.

Copyright (๑) 2020 Palacios-García and Parada. This is an open-access article distributed under the terms of the Creative Commons Attribution License (CC BY).

The use, distribution or reproduction in other forums is permitted, provided the original author(s) and the copyright owner(s) are credited and that the original publication in this journal is cited, in accordance with accepted academic practice. No use, distribution or reproduction is permitted which does not comply with these terms. 